University of Nebraska - Lincoln

DigitalCommons@University of Nebraska - Lincoln

2007

Low-Energy Electron Capture by 6-Aza-2-thiothymine:

Investigations by Electron Attachment and Electron Transmission

Spectroscopies

Stanislav A. Pshenichnyuk

Gordon A. Gallup

Paul Burrow

Follow this and additional works at: https://digitalcommons.unl.edu/physicsburrow

Part of the Atomic, Molecular and Optical Physics Commons

This Article is brought to you for free and open access by the Research Papers in Physics and Astronomy at DigitalCommons@University of Nebraska - Lincoln. It has been accepted for inclusion in Paul Burrow Publications by an authorized administrator of DigitalCommons@University of Nebraska - Lincoln. 


\title{
Low-Energy Electron Capture by 6-Aza-2-thiothymine: Investigations by Electron Attachment and Electron Transmission Spectroscopies
}

\author{
Stanislav A. Pshenichnyuk, ${ }^{1}$ Gordon A. Gallup, ${ }^{2}$ \\ and Paul D. Burrow ${ }^{2}$ \\ 1 Institute of Physics of Molecules and Crystals, Russian Academy of Sciences, \\ October Avenue, 151, Ufa, 450075, Russia \\ 2 Department of Physics and Astronomy, University of Nebraska-Lincoln, \\ Lincoln, Nebraska 68588-0111 \\ Correspondence - S. A. Pshenichnyuk, email sapsh@anrb.ru
}

\begin{abstract}
The interaction of low-energy (o-10 eV) electrons with 6-aza-2-thiothymine is investigated in the gas phase by studies of sharp structure in the total electron scattering cross section and by mass analysis of the stable or long-lived negative ions produced by electron attachment. The most efficient fragmentation process, occurring at $0.15 \mathrm{eV}$, involves the ejection of a closed-shell neutral molecule $\left(\mathrm{CH}_{3} \mathrm{CN}\right)$. $\mathrm{Ab}$ initio calculations support our proposal that this process leads to ring closure to form a stable four-member heterocyclic anion. A long-lived parent anion with an approximate lifetime of 75 microseconds is observed near zero electron energy, and evidence is also seen for the slow decay of this anion by ejection of $\mathrm{CH}_{3} \mathrm{CN}$. Near $3 \cdot 3$ $\mathrm{eV}$, an anion of $\mathrm{m} / \mathrm{e} 41$ is produced that is likely to be a metastable valence anion of bent $\mathrm{CH}_{3} \mathrm{CN}$, but the dipole-bound anion cannot be ruled out.
\end{abstract}

Published in Journal of Physical Chemistry A 111 (2007), pp 11837-11842

doi:10.1021/jpo76765b

Copyright (C) 2007 American Chemical Society. Used by permission.

Submitted August 23, 2007; revised September 18, 2007; published October 26, 2007. 


\section{Introduction}

Temporary negative ion states may lead to bond breaking and stable anion fragments by a number of different mechanisms in complex molecules through the dissociative electron attachment (DEA) process. For example, electron attachment into a normally unoccupied $\sigma^{*}$ (antibonding) orbital typically produces a temporary anion with a repulsive potential surface. Given a sufficiently long lifetime and a fragment with a high electron affinity, the temporary anion may dissociate along a $\sigma$-bond. This process has been studied most extensively in the chloroalkanes. ${ }^{1-5}$ In more complex compounds containing low-lying empty $\pi^{*}$ and $\sigma^{*}$ orbitals, where these labels indicate local symmetries, mixing of the corresponding anion states by through-bond and through-space interactions can greatly enhance the DEA cross sections for breakage along the $\sigma$-bond, owing in part to the longer lifetime of the $\pi^{*}$-resonance. ${ }^{6,7}$ Theoretical predictions of the DEA cross sections, incorporating ab initio calculations along with empirical values for the lifetimes of the uncoupled resonances, quite successfully account for the experimental results in six chloroalkene compounds. ${ }^{8}$

In another mechanism, mixing of diffuse dipole-bound anion states with low-lying anion states created by electron occupation of valence $\sigma^{*}$ orbitals has been invoked to explain a sharp structure appearing in the DEA cross sections of the DNA/RNA bases ${ }^{9}$ and in the total scattering cross sections of halo-substituted bases. ${ }^{10}$ Such vibrational Feshbach resonances (VFRs) may be a general feature of scattering processes in molecules having sufficiently high dipole moments. These few examples illustrate the major DEA mechanisms expected at energies where "shape" resonances are likely to dominate, that is, below roughly $4 \mathrm{eV}$.

The present work describes measurements of anion production and supporting quantum chemical calculations in 6-aza-2-thiothymine (M), a compound that exhibits an unusually rich DEA spectrum in terms of the mechanisms involved. Among these is an electron attachment-induced ring opening accompanied by elimination of a neutral closed-shell molecule $\left(\mathrm{CH}_{3} \mathrm{CN}\right)$. The energetics of this process suggest that the anion fragment has a closed ring structure, the only example of such a gas-phase reaction that we are aware of. A long-lived parent 
anion state is also observed near zero electron energy, and evidence for its slow decay by the process described above is obtained. At higher energies, numerous anion fragments are observed, and two possible structures for the $m / e, 41$ anion are described. Finally, relatively sharp features exist that we attribute to VFR structures.

\section{Experimental Section}

Our investigation was carried out using two experimental techniques: mass resolved electron attachment spectroscopy (EAS) and electron transmission spectroscopy (ETS). ${ }^{11}$

\subsection{Electron Attachment Spectroscopy}

The experimental setup was described in detail previously, ${ }^{12}$ and the general concepts of electron attachment spectroscopy may be found elsewhere..$^{13-15}$ Briefly, electron attachment to single molecules was studied in the gas phase by passing an electron beam through the ionization chamber of a magnetic mass spectrometer, where an equilibrium flow of molecules under investigation was created. The yield of negative ions formed was recorded mass spectrometrically as a function of incident electron energy using a secondary electron multiplier. The pressure inside the collision chamber was kept below $\sim 10^{-6}$ Torr in order to ensure single-collision conditions. The electron energy scale was calibrated by the yield of $\mathrm{SF}_{6}{ }^{-}$from $\mathrm{SF}_{6}$ which gives the well-known resonance peak at $\mathrm{O} \mathrm{eV}$, as well as by $\mathrm{Br}^{-}$from 2-Br-propane (resonant peak at $0.90 \mathrm{eV}$ ), $\mathrm{NH}_{2}{ }^{-}$from $\mathrm{NH}_{3}$ (resonant peak at $5.65 \mathrm{eV}$ ), and $\mathrm{O}^{-}$from $\mathrm{CO}_{2}$ (resonant peaks at 4.3 and $8.1 \mathrm{eV}$ ). No zero-energy peak artifacts were found due to addition of $\mathrm{SF}_{6}$ gas with the present experimental conditions. An electron monochromator was not used, thus the full width at half-maximum (FWHM) of the electron energy distribution estimated by the yield of $\mathrm{SF}_{6}{ }^{-} /$ $\mathrm{SF}_{6}$ was about $0.4 \mathrm{eV}$. The corresponding electron beam current was $1 \mu \mathrm{A}$. These conditions allowed the observation of fragment anions produced with small cross sections. The estimated accuracy of determination of peak energies on the anion yield curves is $\pm 0.1 \mathrm{eV}$. The autodetachment lifetime of metastable parent molecular anions 
was estimated by a method which is based on deflection of the ionic component and comparison of the yield of neutrals formed by autodetachment with the intensity of the total beam of mass selected anions, as described elsewhere. ${ }^{13} \mathrm{~A}$ microsecond time-window is available for such an analysis.

\subsection{Electron Transmission Spectroscopy}

The ETS apparatus is in the format devised by Sanche and Schulz. ${ }^{11}$ Briefly, a magnetically collimated electron beam of well-defined energy was passed through a collision cell containing the target gas, and the transmitted electron current was collected. To enhance resonant structures in the total electron scattering cross section, the derivative technique ${ }^{11}$ was used. The vertical attachment energy (VAE) for formation of a temporary anion state was assigned to the energy of the midpoint between the two extrema appearing in the derivative of unscattered electron current, owing to the presence of a peak in the total scattering cross section. The electron energy scale was calibrated by a small admixture of $\mathrm{N}_{2}$ gas and reference to the sharp structure related to formation of the $\mathrm{N}_{2}^{-}\left({ }^{2} \Pi_{\mathrm{g}}\right)$ state. The corresponding positive extrema in the derivative signal are taken to be at 1.98, $2.22,2.46$, and $2.69 \mathrm{eV}$. The overall error in VAE is $\pm 0.05 \mathrm{eV}$. The use of a trochoidal electron monochromator (TEM) in the form first proposed by Stamatovic and Schul $z^{16}$ allows an electron energy distribution of $50 \mathrm{meV}$ FWHM.

The sample of 6-aza-2-thiothymine (purity 99\%, melting point 218$221^{\circ} \mathrm{C}$ ) was purchased from Aldrich (Product No. 275514) and was used without further treatment. It was evaporated into the reaction chamber at a temperature of approximately $70^{\circ} \mathrm{C}$, which is well below the melting point and decomposition temperature for this compound.

To assign features found in the total electron scattering cross section to resonant states associated with occupation of normally empty molecular orbitals, ab initio Hartree-Fock calculations were performed using the GAMESS ${ }^{17}$ quantum chemical package. The $6-31 \mathrm{G}(\mathrm{d})$ basis set was used for optimization of the geometry of the neutral molecule and for calculation of virtual orbital energies (VOEs) as well. By correlating VOEs against measured VAEs in various families of molecules ${ }^{18,19}$ it is possible to use calculated 
VOEs to predict VAEs. In the present work, a scaling scheme for $\pi^{*}$ resonances based on measured VAEs of the lowest anion states of benzene, naphthalene, pyridine, and pyrimidine was used, as in the case of DNA bases, ${ }^{20}$ in the form VAE $=[\mathrm{VOE}-2.5553] / 1.3749$. To scale $\sigma^{*}$-resonances, the relationship VAE $=[\mathrm{VOE}-2.856] / 1.096$ used earlier for the case of $\mathrm{C}-\mathrm{Cl} \sigma^{*}$ orbitals of chloroalkanes ${ }^{2}$ was employed. The latter scaling is subject to greater error, however, for $\sigma^{\star}$-resonances in the molecule under investigation.

Application of the ETS and EAS techniques together gives a complementary view of resonance effects. Data from the former reflect the total cross sections and energies for formation of temporary anion states and are thus best suited for comparison with theory. EAS, on the other hand, probes DEA cross sections which generally are much smaller than total scattering cross sections and arise from more specific properties of the molecular orbitals, such as their strongly antibonding regions and the electron affinities of the possible product fragments.

\section{Results and Discussion}

\subsection{Temporary Anion States of 6-Aza-2-thiothymine}

The ET spectrum of M is shown in Figure 1. The locations of two pronounced temporary negative ion states are indicated by vertical lines. The VAEs and ETS dip-to-peak separations (shown in parentheses) associated with these resonances are 2.98 (1.01) eV and 4.69 (1.00) eV, respectively. As in the case of DNA bases, ${ }^{20}$ the observation of lowlying anion states in compounds with large electric dipole moments is difficult because of contributions from dipole scattering which increase rapidly as electron energies approach zero electronvolts. The dipole moment of $\mathrm{M}$ is calculated to be $3.4 \mathrm{D}$, high enough to display such behavior. With increased rejection of scattered electrons ${ }^{21}$ a small shoulder is observed at $0.4 \mathrm{eV}$, the only sharp structure observed below $1 \mathrm{eV}$ in the total scattering cross section. The visibility of the dip and peak centered at $1.5 \mathrm{eV}$ in the ET spectrum is a strong function of the scattered electron rejection ${ }^{21}$ and is not attributed to a temporary anion state. 


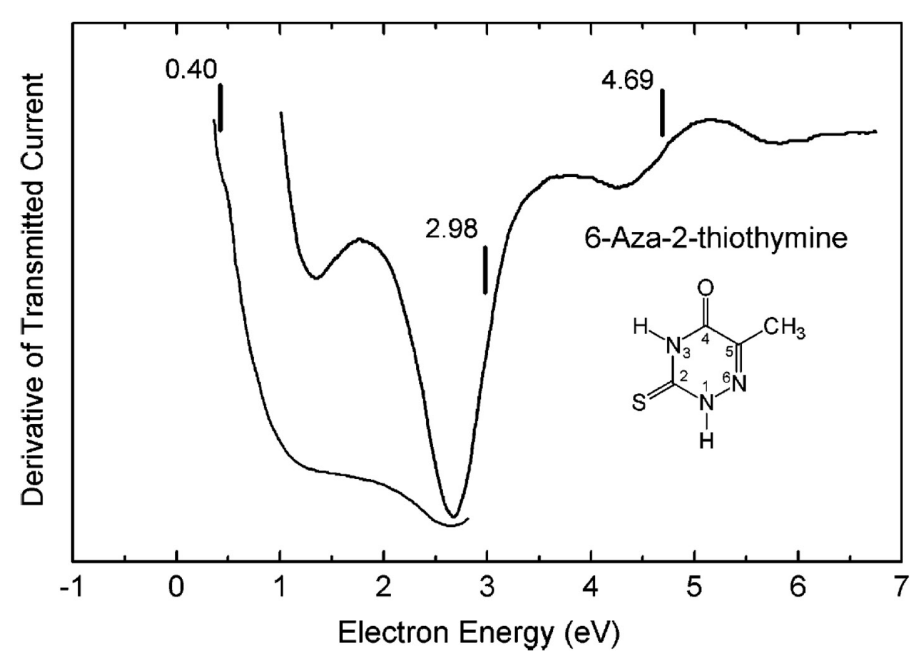

Figure 1. The derivative with respect to energy of electron current transmitted through 6-aza-2-thiothymine. The lower curve is acquired with higher scattered electron rejection.

Table 1 summarizes our tentative resonance assignments based on the observed VAEs and the calculated and scaled VOEs. For reference, Figure 2 illustrates the significant lower-lying virtual orbitals of M. The lowest valence anion state of $\mathrm{M}$, corresponding to occupation of the lowest unoccupied molecular orbital (LUMO) $\left(\pi_{1}^{*}\right)$, is predicted to be stable by approximately $0.4 \mathrm{eV}$ and thus is not observable by ETS. The scaled VOE associated with occupation of the LUMO+1 $\left(\pi_{2}{ }^{*}\right)$ orbital by the incoming electron is $0.20 \mathrm{eV}$. A slight instability of a mainly $\pi^{*}{ }_{\mathrm{C}=\mathrm{S}}$ anion state mixed with adjacent nitrogen lone pairs MOs is fully consistent with previous ETS data. ${ }^{22}$ As suggested above, it is

Table 1. Virtual Orbital Energies, Their Scaled Values, and Corresponding Vertical Attachment Energies as Observed by Electron Transmission Spectroscopy in 6-Aza-2-thiothymine

\begin{tabular}{llrrr} 
& orbital & VOE $(\mathrm{eV})$ & scaled VOE $(\mathrm{eV})$ & VAE $(\mathrm{eV})$ \\
\hline 1 & LUMO,$\pi_{1}{ }^{*}$ & 2.0137 & -0.39 & \\
2 & LUMO+1, $\pi_{2}{ }^{*}$ & 2.8354 & 0.20 & $<0.5$ \\
3 & LUMO+2, $\sigma^{*}$ & 5.2791 & 2.21 & \\
4 & LUMO+5, $\pi_{3}{ }^{*}$ & 7.2546 & 3.42 & 2.98 \\
5 & LUMO+6, $\sigma_{\mathrm{C}=\mathrm{S}}{ }^{*}$ & 7.3063 & 4.06 & \\
6 & LUMO $+9, \pi_{4}{ }^{*}$ & 9.1676 & 4.81 & 4.69 \\
\hline
\end{tabular}




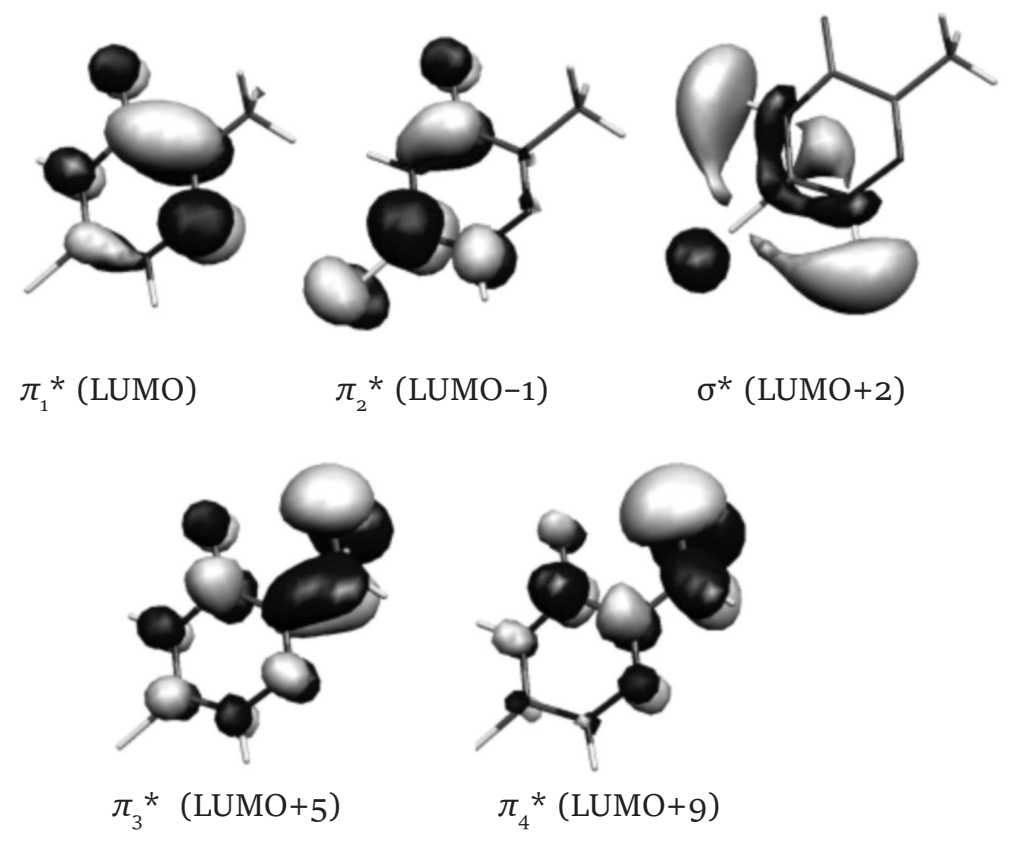

Figure 2. Molecular orbital plots of the significant virtual orbitals of 6-aza2-thiothymine.

likely that this resonance is obscured by the large contribution from dipole scattering at low energy, but a priori it cannot be ruled out that this resonance could correspond to the narrow $0.4 \mathrm{eV}$ shoulder. We associate the relatively intense ETS feature found at $2.98 \mathrm{eV}$ with occupation of the $\pi_{3}{ }^{*}$ orbital, which is LUMO +5 in M, with a scaled VOE of $3.42 \mathrm{eV}$. The relatively narrow structure at $4.69 \mathrm{eV}$ is likely to be a core-excited resonance mixed in part with a higher-lying $\pi^{*}$ shape resonance primarily associated with $\sigma_{\mathrm{CH}}$ orbitals of the $\mathrm{CH}_{3}{ }^{-}$group coupled with the $\pi$-system of the heterocycle.

Structures in the ET spectra arising from $\sigma^{*}$ orbitals of the second-row elements do not appear readily, either because of their broad widths or their overlap with stronger $\pi^{*}$-resonances. Nevertheless, by analogy to uracil and the DNA bases ${ }^{9}$ we expect that the lowest valence $\sigma^{*}$ orbital (LUMO+2, shown in Figure 2), primarily located on the $\mathrm{N}_{1}-\mathrm{H}$ and $\mathrm{N}_{3}-\mathrm{H}$ bonds, will play a role in the dissociative attachment processes discussed below because of its coupling with the dipole-bound state produced by the supercritical dipole moment. Although ETS features associated with $\sigma_{\mathrm{CS}}{ }^{*}$ orbitals have been observed by ETS in the range $2.2-3.6 \mathrm{eV},{ }^{23}$ that associated with the $\mathrm{C}=\mathrm{S}$ bond in 
M (LUMO+6) is expected to lie higher because of the shorter bond distance. The estimated scaled VOE is $4.06 \mathrm{eV}$, but it should be remembered that the scaling procedure is less proven for $\sigma^{\star}$-resonances other than those associated with $\mathrm{C}-\mathrm{Cl}$ bonds.

\subsection{Fragmentation of 6-Aza-2-thiothymine by Low-Energy Electrons}

The most significant results from the electron attachment measurements at low energies are collected in Figure 3. The dominant fragmentation channel, by at least 2 orders of magnitude, corresponds to formation of the $\left[\mathrm{M}-\mathrm{CH}_{3} \mathrm{CN}\right]^{-}$ion $(\mathrm{m} / \mathrm{e}$ 102) with a maximum yield at approximately $0.15 \mathrm{eV}$. This result is quite different from that in the related thymine (T) molecule, ${ }^{24,25}$ where it was found that the most intense decay channel following low-energy electron attachment is by release of one hydrogen atom, that is, formation of the $[\mathrm{T}-\mathrm{H}]^{-}$closedshell ion. Formation of $[\mathrm{M}-\mathrm{H}]^{-}$has also been detected in the present work but with more modest relative intensity as seen in Figure 3 and will be discussed later.

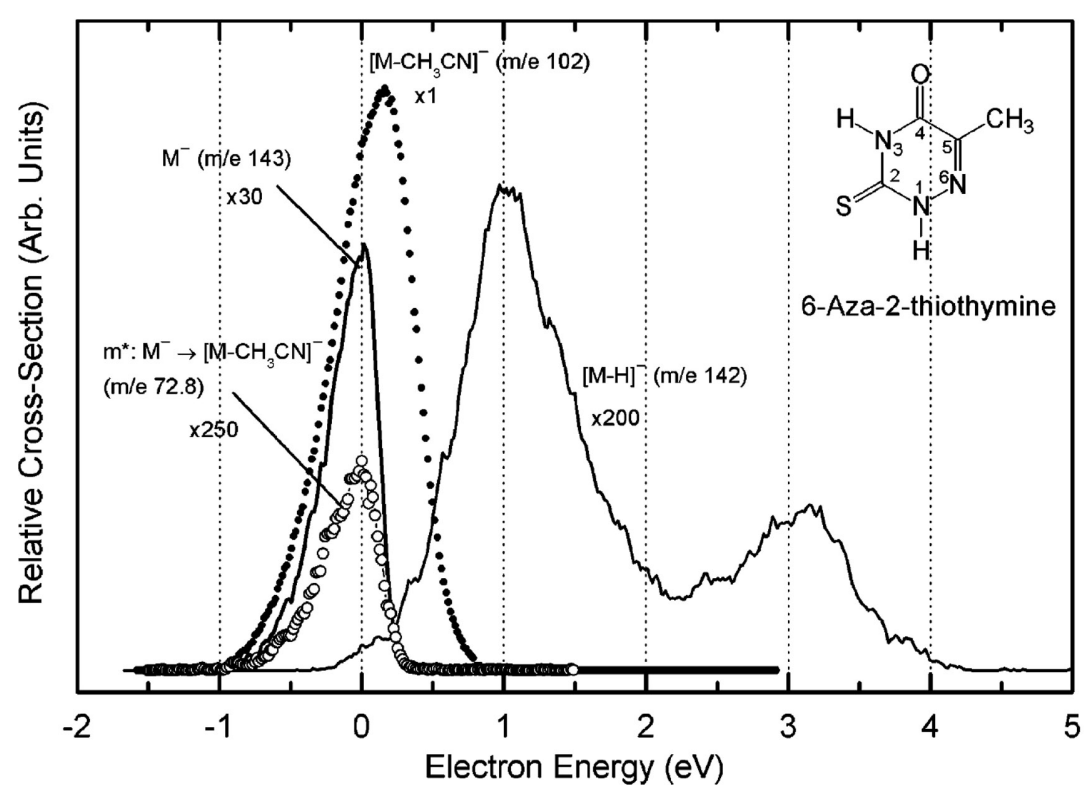

Figure 3. Anion yields as a function of electron energy for $\left[\mathrm{M}-\mathrm{CH}_{3} \mathrm{CN}\right]^{-}, \mathrm{M}^{-}$, $[\mathrm{M}-\mathrm{H}]^{-}$and the metastable process appearing at $\mathrm{m} / \mathrm{e} 72.8$. 
Compound $\mathrm{M}$ differs from a 2-thio substituted thymine only by the presence of a nitrogen atom in the ring at position 6 . Thus, a prepared "fragment" of acetonitrile $\left(\mathrm{CH}_{3} \mathrm{CN}\right)$ exists in the heterocycle that requires only the breaking of two single bonds $\left(\mathrm{C}_{4}-\mathrm{C}_{5}\right.$ and $\mathrm{N}_{1}-$ $\mathrm{N}_{6}$ ) to release a neutral molecule of acetonitrile from the temporary parent molecular anion. We attribute this DEA process to the shape resonance produced by occupation of the $\pi_{2}{ }^{*}$ orbital in M. The corresponding DEA peak energy ( $0.15 \mathrm{eV})$ agrees well with the scaled VOE $(0.20 \mathrm{eV})$ for occupation of LUMO+1 by the incident electron. The orbital picture in Figure 2 shows that $\mathrm{LUMO}+1$ is antibonding between $\mathrm{N}_{1}-\mathrm{N}_{6}$ and between $\mathrm{C}_{4}-\mathrm{C}_{5}$, as would be appropriate for release of the $\mathrm{CH}_{3} \mathrm{CN}$ group.

Because of the low energy at which the DEA process occurs, either the fragment bearing the electron must have a very large electron affinity or the underlying neutral rearrangement must have a low energy. The latter is best achieved if the number of bonds formed equals the number broken. We suggest that the reaction shown in the inset below satisfies this requirement, in addition to having the least possible atom rearrangement.

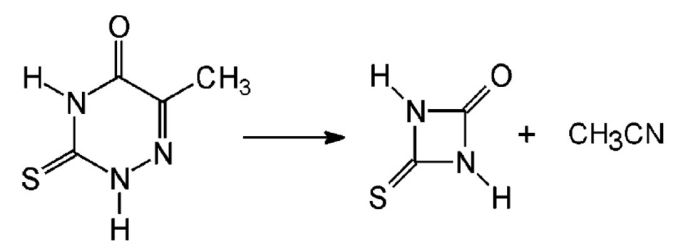

This would be an isodesmic process, as defined by Hehre et al., ${ }^{26}$ except for the change in bond type. Consequently the reaction should be roughly isoergic. Calculations at the 6-311G-(spd) level have been carried out to test this hypothesis. The optimum geometries of $\mathrm{M}$, the four-membered heterocycle 2-thiono-1,3-azetidine-2,4-dione (TAD), and $\mathrm{CH}_{3} \mathrm{CN}$ have been determined at the RHF-MP2 level using the GAMESS suite. ${ }^{17}$ The resulting energy required for the reaction in the inset is $0.5756 \mathrm{eV}$. When this is further corrected for ZPE differences, the asymptotic energy for the neutral reaction is $0.3741 \mathrm{eV}$. Thus an adiabatic electron affinity for TAD in excess of this value will make the anion process exoergic. We note also that ring closure after ejection of $\mathrm{CH}_{3} \mathrm{CN}$ to form [TAD]- is also consistent with the bonding nature of the wave function between $\mathrm{N}_{1}$ and $\mathrm{C}_{4}$ in the $\pi_{2}{ }^{*}$ orbital of $\mathrm{M}$. 
Our calculations show that the LUMO energy of TAD is $2.1715 \mathrm{eV}$ at the HF/6-31G(d) level of theory. The corresponding scaled value is $-0.333 \mathrm{eV}$, corresponding to a positive vertical electron affinity. A more detailed $\mathrm{ab}$ initio calculation of the adiabatic electron affinity, found to be $1.4989 \mathrm{eV}$, has been obtained at the MP2 level and the methods are discussed fully elsewhere. ${ }^{27}$ Combining this with the $\phi E$ of the neutral reaction, the DEA process is predicted to be exoergic by $1.125 \mathrm{eV}$. In our experiment, no neutral component arising from electron autodetachment of the product negative ion was found within the sensitivity of our measurements, implying that the $\left[\mathrm{M}-\mathrm{CH}_{3} \mathrm{CN}\right]^{-}$ion is stable in this regard or, strictly speaking, that its mean autodetachment lifetime is $>1 \mathrm{~ms}$.

We next discuss the yield of $[\mathrm{M}-\mathrm{H}]^{-}$shown in Figure 3. As observed in thymine and many other biologically relevant molecules, for example, the DNA/RNA bases ${ }^{25,28}$ and organic acids, ${ }^{29-31}$ ejection of an $\mathrm{H}$ atom is the lowest-lying DEA process. The shape of the yield is similar to that observed earlier for uracil and thymine, ${ }^{24,25}$ although the poorer energy resolution employed here makes a close comparison difficult. The main peak lies at $1.02 \mathrm{eV}$, very close to the value (1.05 eV) observed in thymine ${ }^{25}$ and uracil. ${ }^{10}$ In the latter compounds, this feature has been attributed ${ }^{10}$ to the formation of a vibrational Feshbach resonance (VFR) ${ }^{32}$ created by mixing of the dipole-bound anion state with the lowest-lying $\sigma^{\star}$ valence anion state. Because of the supercritical dipole moment of $\mathrm{M}$, the same mechanism should apply. Furthermore, the lowest valence $\sigma^{*}$ orbital, LUMO+2 shown in Figure 2, is similar to that in thymine and uracil, namely, strongly antibonding between $\mathrm{N}_{1}-\mathrm{H}$ and $\mathrm{N}_{3}-\mathrm{H}$.

In thymine, other sharp features also appear in the attachment spectra $^{9}$ that cannot be resolved in the present experiment. These peaks are associated with other vibrational levels of the dipole bound anion state. It is possible that the small shoulder in the ET spectrum of $\mathrm{M}$ appearing at approximately $0.4 \mathrm{eV}$ in Figure 1 may correspond to a low-lying VFR, as observed in the ET spectra of halo-substituted uracils. ${ }^{10}$

The energy of the second peak in the $[\mathrm{M}-\mathrm{H}]^{-}$anion yield matches that of the $\pi_{3}{ }^{*}$-resonance in $\mathrm{M}$. In this case, the dissociative attachment process takes place through coupling of the $\pi_{3}{ }^{*}$ and $\sigma_{\mathrm{NH}}{ }^{*}$ valence orbitals upon out-of-plane distortions. The same mixing was invoked ${ }^{9}$ 
in thymine between its $\pi_{2}{ }^{*}$ and $\sigma_{\mathrm{NH}}{ }^{*}$ anion states to explain peaks occurring just above the $1.05 \mathrm{eV}$ feature.

Before continuing with our discussion of the anion fragments produced by DEA, we address the remaining data shown in Figure 3.

\subsection{Production of the Parent Molecular Negative Ion of 6-Aza-2-thiothymine}

The long-lived parent molecular negative ion $\mathrm{M}^{-}(m / e$ 143) was observed very close to zero energy of the incident electrons as shown in Figure 3. The FWHM of the anion yield for the parent anion $\mathrm{M}^{-}$is instrumental and has the same shape and FWHM as that of $\mathrm{SF}_{6}{ }^{-}$. There is no evidence for a contribution from a second resonant state close to zero energy. We associate the formation of $\mathrm{M}^{-}$with occupation of the LUMO $\left(\pi_{1}^{*}\right)$ of M in a vibrationally excited level of the stable anion state.

The yield of the corresponding neutral component at $m / e 143$ has a maximum at the same electron energy as for $\mathrm{M}^{-}$and decreases by a factor of 25 in relation to the negative ion yield. Thus the estimated autodetachment lifetime of the parent negative ion is $75 \mu$ s near zero electron energy at the peak maximum.

A diffuse metastable mass peak was also found in the negative ion mass spectra of $\mathrm{M}$ at a fractional mass number of $\mathrm{m} / \mathrm{e} 72.8$ as shown in Figure 3. The energy dependence is instrumental in width and similar to that seen in the production of $\mathrm{M}^{-}$. Such a metastable anion corresponds to the fragmentation process $\mathrm{M}^{-} \rightarrow\left[\mathrm{M}-\mathrm{CH}_{3} \mathrm{CN}\right]^{-}+\mathrm{CH}_{3} \mathrm{CN}$, which is observable only if it takes place close to the input aperture of the mass-analyzing magnet.33 During the time-of-flight of the parent anion from the point of its formation inside the ionization chamber to the input aperture of the analyzing magnet, 10-15 $\mu \mathrm{s}$, this metastable process yields a relative intensity that is only $0.15 \%$ of that for $\mathrm{M}^{-}$. We assume that formation of $\left[\mathrm{M}-\mathrm{CH}_{3} \mathrm{CN}\right]^{-}$close to zero energy of the incident electron is connected with the $\pi_{1}^{*}$ resonant state, as in the formation of the parent anion. Although the bonding and antibonding characteristics of this orbital are much less favorable than those of $\pi_{2}{ }^{*}$ for ejection of $\mathrm{CH}_{3} \mathrm{CN}$, the time scale is enormously longer and may permit the necessary energy to be concentrated on the reaction coordinate responsible for this DEA process. Again, to account for the 
zero energy threshold of this process, it appears that $\left[\mathrm{M}-\mathrm{CH}_{3} \mathrm{CN}\right]^{-}$ must be identified with $\mathrm{TAD}^{-}$.

\subsection{Production of Additional Anion Fragments of 6-Aza-2-thiothymine}

Figure 4 displays the relative cross sections for fragments with $\mathrm{m} / \mathrm{e}$ ranging from 26 to 74. Table 2 summarizes all the anions observed here along with the proposed structure, peak energies, and relative intensities.

We focus first on evidence for a fragment anion with $\mathrm{m} / \mathrm{e} 41$ and a maximum yield at $3.37 \mathrm{eV}$. In principle, there are several structures which may be assigned to this value of $\mathrm{m} / \mathrm{e}$. They cannot include a sulfur atom and could be assigned to $[\mathrm{CNNH}]^{-},[\mathrm{COCH}]^{-},\left[\mathrm{C}_{2} \mathrm{H}_{2} \mathrm{CH}_{3}\right]^{-}$, $\left[\mathrm{C}_{2} \mathrm{H}_{2} \mathrm{NH}\right]^{-}$, or $\left[\mathrm{CH}_{3} \mathrm{CN}\right]^{-}$. The first requires breaking of three bonds, the second requires rearrangement in addition, and the next two seem unlikely to form by DEA to 6-aza-2-thiothymine because of the very complex rearrangement process. Isotopic analysis is impossible in this case because of the intense $[\mathrm{OCN}]^{-}$fragment anion at $\mathrm{m} / e \mathrm{e} 2 \mathrm{which}$ obscures the yield of the isotopic line from the m/e 41 fragment. Formation of $\left[\mathrm{CH}_{3} \mathrm{CN}\right]^{-}$requires breaking of only two bonds, and the remaining neutral biradical may close to the four-membered cyclic TAD structure alluded to earlier and, in such a way, reduce the total energy of the final-state products.

The $\left[\mathrm{CH}_{3} \mathrm{CN}\right]^{-}$anion has been reported previously following electron attachment to acetonitrile clusters where it was assigned to a dipole-bound state. ${ }^{34}$ The corresponding anion yield peaked at an incident electron energy of $8.5 \mathrm{eV}$. Although a dipole-bound anion state of $\mathrm{CH}_{3} \mathrm{CN}$ is known with a binding energy of $11.5 \mathrm{meV}$, 35 it is useful to examine the possibility of a stable or metastable valence anion. ETS in acetonitrile shows a resonant feature at $2.84 \mathrm{eV}$ associated with occupation of the $\pi^{*}$ LUMO by the incoming electron. ${ }^{36,37}$ The only possibility for a valence-bound anion state is if the molecule is bent and the anion is thus stabilized.

To test this hypothesis, the geometries of $\mathrm{CH}_{3} \mathrm{CN}^{-}$were determined at the $6-311 \mathrm{G}(\mathrm{spd})$ level, optimizing all internal coordinates except the $\mathrm{N}-\mathrm{C}-\mathrm{C}$ angle, which was held fixed at a series of values. The methods to be described in ref 27 were used to correct the anion energies 


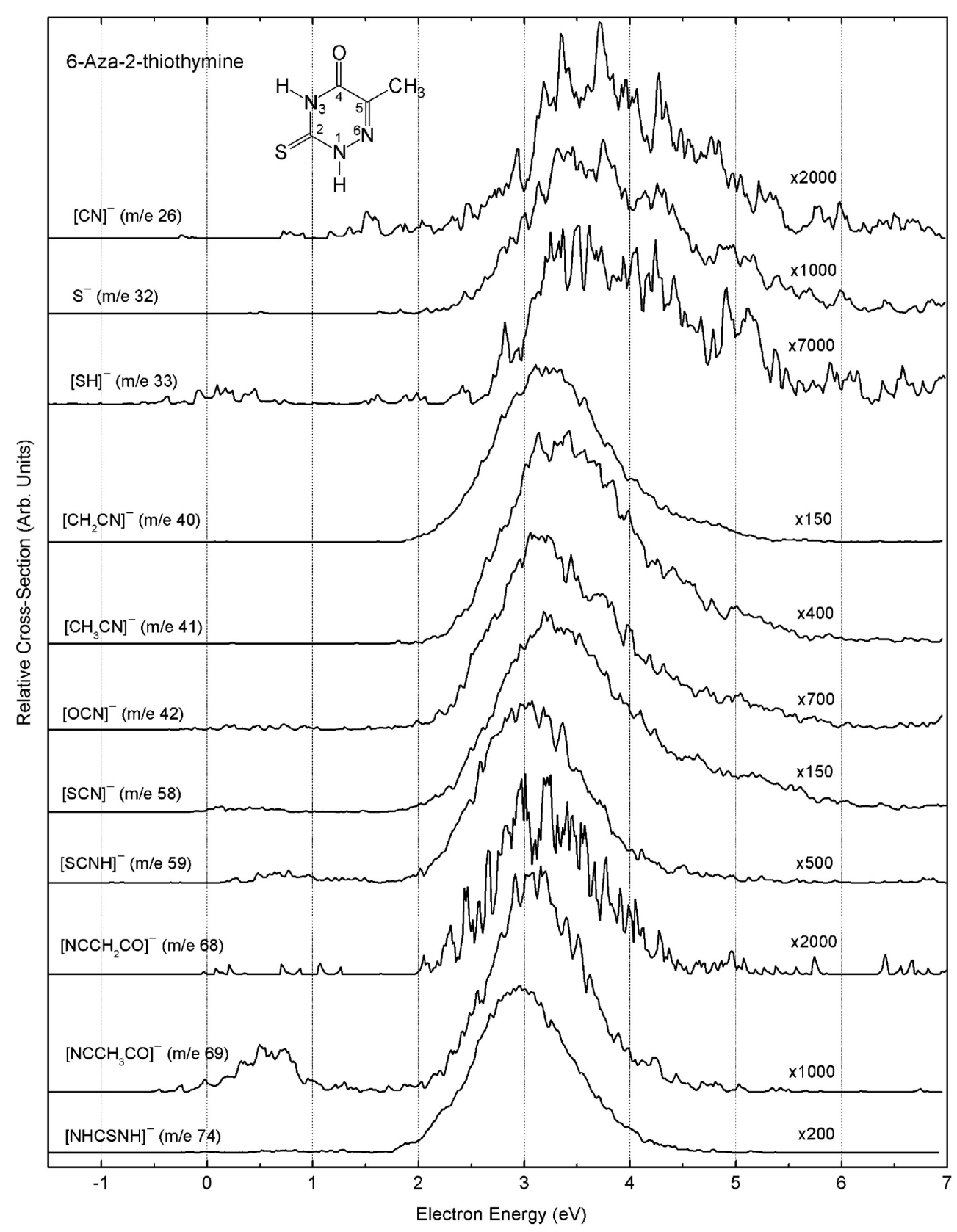

Figure 4. Yields of anions with $\mathrm{m} / \mathrm{e}$ in the range from 26 to 74 as a function of electron energy.

with respect to the neutral. A minimum in the anion energy was found between $60^{\circ}$ and $65^{\circ}$, and the vertical detachment energy was approximately $1.12 \mathrm{eV}$. At this angle, the anion state lies $0.72 \mathrm{eV}$ above the ground-state neutral in its optimized (linear) geometry. Thus, the 
Table 2. Anions Observed in the Negative Ion Mass Spectra of 6-Aza-2-thiothymine, Proposed Structures, Peak Energies, and Relative Intensities

\begin{tabular}{lllcc} 
& $m / e$ & anion structure & peak energy $(\mathrm{eV})$ & peak intensity (\%) \\
\hline 1 & 102 & {$\left[\mathrm{M}-\mathrm{CH}_{3} \mathrm{CN}\right]^{-}$} & 0.15 & 100 \\
2 & 143 & $\mathrm{M}^{-}$ & 0.0 & 2.4 \\
3 & 58 & {$[\mathrm{SCN}]^{-}$} & 3.24 & 0.63 \\
4 & 40 & {$\left[\mathrm{CH}_{2} \mathrm{CN}\right]^{-}$} & 3.20 & 0.57 \\
5 & 74 & {$\left[\mathrm{NHCSNH}^{-}\right.$} & 2.95 & 0.43 \\
6 & 142 & {$[\mathrm{M}-\mathrm{H}]^{-}$} & 1.02 & 0.41 \\
& & & 3.16 & 0.14 \\
7 & 41 & {$\left[\mathrm{CH}_{3} \mathrm{CN}\right]^{-}$} & 3.37 & 0.25 \\
8 & 59 & {$\left[\mathrm{SCNH}^{-}\right.$} & 0.84 & $<0.05$ \\
& & & 3.05 & 0.16 \\
9 & 42 & {$[\mathrm{OCN}]^{-}$} & 3.14 & 0.14 \\
10 & 69 & {$\left[\mathrm{NCCH}_{3} \mathrm{CO}\right]^{-}$} & 0.63 & $<0.05$ \\
& & & 3.10 & 0.11 \\
11 & 32 & $\mathrm{~S}^{-}$ & 3.60 & 0.08 \\
12 & 68 & {$\left[\mathrm{NCCH}_{2} \mathrm{CO}\right]^{-}$} & 3.18 & $<0.05$ \\
13 & 26 & {$\left[\mathrm{CN}^{-}\right.$} & 3.73 & $<0.05$ \\
14 & 33 & {$\left[\mathrm{SH}^{-}\right.$} & 3.68 & $<0.05$ \\
15 & 72.8 & $\mathrm{~m}^{*}: 143 \rightarrow 102$ & 0.0 & 0.15 \\
\hline
\end{tabular}

valence anion is metastable. Given that the anion geometry at its minimum is quite close to that of the fragment imbedded in $\mathrm{M}$, the association of the $m / e 41$ peak with the bent valence anion appears quite reasonable, and we note in this context that both cases have the same $\mathrm{sp}^{2}$ hybridization at the non-methyl carbon atom. The results described here are quite analogous to the observation of the $\left[\mathrm{CO}_{2}\right]^{-}$negative ion by DEA to cyclic anhydrides. ${ }^{38}$ We conclude that the possibility that the anion is in the dipole-bound state seems less likely to us but it cannot be ruled out.

Numerous low-intensity fragmentation processes appear within the electron energy range of about $2-5 \mathrm{eV}$ centered at approximately $3.2 \mathrm{eV}$. We associate the production of these fragments with the $\pi_{3}{ }^{*}$ anion state and core-excited resonances in $\mathrm{M}$ at 2.98 and $4.69 \mathrm{eV}$, respectively. The $\left[\mathrm{CH}_{2} \mathrm{CN}\right]^{-}(\mathrm{m} / \mathrm{e} 4 \mathrm{O})$ fragment peaking at $3.2 \mathrm{eV}$ is also observed 39 as the most intense fragment formed in DEA to acetonitrile and occurs at the same energy. 
Fragments $\left[\mathrm{NCCH}_{2} \mathrm{CO}\right]^{-}(\mathrm{m} / \mathrm{e} 68)$ and $\left[\mathrm{NCCH}_{3} \mathrm{CO}\right]^{-}(\mathrm{m} / e$ 69), which differ from $\left[\mathrm{CH}_{2} \mathrm{CN}\right]^{-}$and $\left[\mathrm{CH}_{3} \mathrm{CN}\right]^{-}$by addition of the $\mathrm{CO}$ group, are observed to peak at electron energies of 3.1-3.2 eV. It should be noted that the fragment with $\mathrm{m} / \mathrm{e} 6 \mathrm{~g}$ corresponds to the carbon cycle divided in half by breaking of the $\mathrm{N}_{3}-\mathrm{C}_{4}$ and $\mathrm{N}_{1}-\mathrm{N}_{6}$ bonds. The complementary fragment ion [NHCSNH$]^{-}(\mathrm{m} / \mathrm{e}$ 74) is much more intense and the maximum of its yield is slightly shifted to lower energy. Previously observed in DEA to thymine, ${ }^{40}$ the fragment anion [OCN]- was also found in electron attachment to $\mathrm{M}$ along with the $[\mathrm{SCN}]^{-}$fragment. The relative yield of $[\mathrm{CN}]^{-}$seems to be much lower than reported for thymine in ref 40 . No negative ion signal was observed corresponding to formation of $\mathrm{O}^{-}(\mathrm{m} / \mathrm{e} 16)$, in contrast to results in thymine. This implies that in the case of DEA to thymine only the oxygen atom attached to carbon at the 2-position may be released by attachment of low-energy electrons.

\section{Conclusions}

The interaction of low-energy (o-10 eV) electrons with 6-aza-2-thiothymine in the gas phase has been investigated by electron attachment spectroscopy and electron transmission spectroscopy. The main conclusions are the following.

The nitrogen atom in the heterocycle dramatically changes the fragmentation pattern of 6-aza-2-thiothymine at low electron energies compared to that of thymine, with release of a neutral acetonitrile molecule being the dominant channel. The corresponding fragment negative current peaks at $0.15 \mathrm{eV}$ and is attributed to occupation of the $\pi_{2}{ }^{*}$ orbital which is LUMO+1 of 6-aza-2-thiothymine. Ab initio calculations indicate that a rearrangement of the fragment anion to form a four-membered cycle is energetically favored.

Mass spectrometric observation of the parent molecular anion of 6-aza-2-thiothymine at zero energy indicates that the neutral molecule possesses a positive adiabatic electron affinity. The autodetachment lifetime of the parent anion formed near zero electron energy is estimated to be $75 \mu \mathrm{s}$. Ab initio calculations indicate that the vertical electron affinity of the molecule is also positive. A slow decay process of the parent anion by ejection of $\mathrm{CH}_{3} \mathrm{CN}$ was also observed. 
Two broad resonant features found in the electron transmission spectra at 2.98 and $4.69 \mathrm{eV}$ are associated with occupation of the $\pi_{3}{ }^{*}$ orbital and a core-excited resonance, respectively, and produce numerous fragment anions by DEA. Among these, an anion of $m / e 41$ was observed that we suggest is a metastable valence anion state of $\mathrm{CH}_{3} \mathrm{CN}$ in a bent geometry.

Acknowledgment The authors are grateful to Alberto Modelli for useful comments. This work was supported by US Civilian Research and Development Foundation (CRDF) Grant No. RC1-2515-UF-03 as well as by the Russian Foundation for Basic Research (RFBR) Grant No. o6-03-32059-a.

\section{References and Notes}

(1) See, for example, Aflatooni, K.; Burrow, P. D. J. Chem. Phys. 200o, 113, 1455.

(2) Aflatooni, K.; Gallup, G. A.; Burrow, P. D. J. Phys. Chem. A 2000, 104, 7359.

(3) Gallup, G. A.; Aflatooni, K.; Burrow, P. D. J. Chem. Phys. 2003, 118, 2562.

(4) Modelli, A.; Scagnolari, F.; Distefano, G.; Guerra, M.; Jones, D. Chem. Phys. 1990, 145, 89 .

(5) Guerra, M.; Jones, D.; Distefano, G.; Scagnolari, F.; Modelli, A. J. Chem. Phys. 1991, 94, 484 .

(6) See, for example, Pearl, D. M.; Burrow, P. D.; Nash, J. J.; Morrison, H.; Jordan, K. D. J. Am. Chem. Soc. 1993, 115, 9876.

(7) Pearl, D. M.; Burrow, P. D.; Nash, J. J.; Morrison, H.; Nachtigallova, D.; Jordan, K. D. J. Phys. Chem. 1995, 99, 12379.

(8) Burrow, P. D.; Gallup, G. A. J. Chem. Phys. 2006, 125, 154309.

(9) Burrow, P. D.; Gallup, G. A.; Scheer, A. M.; Denifl, S.; Ptasinska, S.; Märk, T.; Scheier, P. J. Chem. Phys. 2006, 124, 124310, and references therein.

(10) Scheer, A. M.; Aflatooni, K.; Gallup, G. A.; Burrow, P. D. Phys. Rev. Lett. 2004, 92, 068102.

(11) Sanche, L.; Schulz, G. J. Phys. Rev. A 1972, 5, 1672.

(12) Pshenichnyuk, S. A.; Asfandiarov, N. L. Eur. J. Mass Spectrom. 2004, 10/4, 477.

(13) Khvostenko, V. I. Negative Ion Mass Spectrometry in Organic Chemistry; Nauka: Moscow, 1981.

(14) Christophorou, L. G. Electron-Molecule Interactions and their Applications; Academic Press: Orlando, 1984.

(15) Illenberger, E.; Momigny, J. Gaseous Molecular Ions, Vol. 2.; Springer-Verlag: New York, 1992.

(16) Stamatovic, A.; Schulz, G. J. Rev. Sci. Instrum. 1970, 41, 423. 
(17) Schmidt, M. W.; Baldridge, K. K.; Boatz, J. A.; Elbert, S. T.; Gordon, M. S.; Jensen, J. H.; Koseki, S.; Matsunaga, N.; Nguyen, K. A.; Su, S. J.; Windus, T. L.; Dupuis, M.; Montgomery, J. A. J. Comput. Chem. 1993, 14, 1347, see also http://www.msg.ameslab.gov/GAMESS/GAMESS.html

(18) Chen, D.; Gallup, G. A. J. Chem. Phys. 1990, 93, 8893.

(19) Staley, S. W.; Strnad, J. T. J. Phys. Chem. 1994, 98, 116.

(20) Aflatooni, K.; Gallup, G. A.; Burrow, P. D. J. Phys. Chem. A 1998, 102, 6205.

(21) Johnston, A. R.; Burrow, P. D. J. Electron Spectrosc. Relat. Phenom. 1982, 25, 119.

(22) Modelli, A.; Jones, D.; Rossini, S.; Distefano, G. Tetrahedron 1984, 40, 3257.

(23) Modelli, A. Trends Chem. Phys. 1997, 6, 57.

(24) Abouaf, R.; Pommier, J.; Dunet, H. Int. J. Mass Spectrom. 2003, 226, 397.

(25) Denifl, S.; Ptasinska, S.; Cingel, M.; Matejcik, S.; Scheier, P.; Märk, T. D. Chem. Phys. Lett. 2003, 377, 74.

(26) Hehre, W. J.; Radom, L.; Pople, J. A.; Schleyer, P. v. R. Ab Initio Molecular Orbital Theory; Wiley and Sons: New York, 1986.

(27) Gallup, G. A. In preparation.

(28) Gohlke, S.; Abdoul-Carime, H.; Illenberger, E. Chem. Phys. Lett. 2003, 380, 595.

(29) Asfandiarov, N. L.; Pshenichnyuk, S. A.; Fokin, A. I.; Lukin, V. G.; Fal'ko, V. S. Rapid Commun. Mass Spectrom. 2002, 16, 1760.

(30) Pelc, A.; Sailer, W.; Scheier, P.; Probst, M.; Mason, N. J.; Illenberger, E.; Märk, T. D. Chem. Phys. Lett. 2002, 361, 277.

(31) Sailer, W.; Pelc, A.; Probst, M.; Limtracul, J.; Scheier, P.; Illenberger, E.; Märk, T. D. Chem. Phys. Lett. 2003, 378, 250.

(32) Hotop, H.; Ruf, M.-W.; Allan, M.; Fabrikant, I. I. Adv. At. Mol. Opt. Phys. 2003, 49, 85 .

(33) Beynon, J. H. Mass Spectrometry and its Applications to Organic Chemistry; Elsevier Publishing Company: Amsterdam, 1960.

(34) Hashemi, R.; Illenberger, E. J. Phys. Chem. 1991, 95, 6402.

(35) Desfrançois, C.; Abdoul-Carime, H.; Khelifa, N.; Schermann, J. P. Phys. Rev. Lett. 1994, 73, 2436.

(36) Burrow, P. D.; Howard, A. E.; Johnston, A. R.; Jordan, K. D. J. Phys. Chem. 1992, 96, 7570 .

(37) Hitchcock, A. P.; Tronc, M.; Modelli, A. J. Phys. Chem. 1989, 93, 3068.

(38) Cooper, C. D.; Compton, R. N. J. Chem. Phys. 1973, 59, 3550.

(39) Sailer, W.; Pelc, A.; Limao-Vieira, P.; Mason, N. J.; Limtracul, J.; Scheier, P.; Probst, M.; Märk, T. D. Chem. Phys. Lett. 2003, 381, 216.

(40) Huels, M. A.; Hahndorf, I.; Illenberger, E.; Sanche, L. J. Chem. Phys. 1998, 108, 1309 . 